\title{
Biología molecular en Infectología. Parte II: Diagnóstico molecular de agentes infecciosos
}

\author{
ALEJANDRO CORVALÁN R. ${ }^{1,2}$, FRANCISCO AGUAYO G. ${ }^{1,3}$, \\ JORGE LÉVICAN G. ${ }^{1}$ e IGNACIO CORVALÁN V. ${ }^{1}$
}

\section{Molecular biology in infectious diseases - Part II: Molecular diagnosis of infectious agents}

The diagnostic applications of the molecular biology in infectious diseases are wide and applicable to any diagnostic problem. In the Herpesviridae family, the most used methods are those based on the amplification of DNA polymerase gene for the detection of HSV 1 and 2, varicela-zoster, citomegalovirus, Epstein Barr virus and HHV6 simultaneously. This methodology has been able of detect the coinfection of HSV1 and VZV in samples of CNS fluid. In citomegalovirus, molecular methods are used in the monitoring of the reactivation of CMV in immunosuppressed patients and are able to detect viral reactivation within 1 week before symptoms. The molecular methods are also able to identify the Epstein-Barr virus in a proportion of 8 to $20 \%$ of gastric cancer cases harboring a unique strain in spite of the presence multiples strains in the healthy population. These associations between virus and cancer have also been described for the human papilloma virus and esophageal and lung cancer. In bacterial agents, the detection and quantification of Bordetella pertussis is another interesting application since it might become a method for rapid diagnosis and predictive of severity in children less than 6 months old. The identification of Helicobacter pylori strains in relation to gastric cancer and peptic ulcer disease and the characterization of strains of methicillin resistant Staphylococcus aureus are other examples of potential applications of the molecular methods in typing microorganisms. In the diagnosis of respiratory tract infectious agents such as Mycobacterium tuberculosis, Pneumocystis carinii and atypical agents, the molecular methods allow the diagnosis in non-invasive samples. Finally, these new methodologies also contribute to the diagnosis of systemic mycotic agents (Candidiasis and Aspergillosis) particularly in immunosuppressed patients.

Key words: Infectious disease; Molecular biology; Molecular diagnosis.

\section{Introducción}

Las aplicaciones diagnósticas de la biología molecular son extremadamente variadas y básicamente son aplicables a cualquier problema diagnóstico asociado a procesos biológicos. Actualmente las principales aplicaciones están en enfermedades infecciosas, oncológicas y genéticas. En enfermedades infecciosas algunas de las principales aplicaciones diagnósticas se entregan en la Tabla 1. Esta tabla muestra una visión panorámica de usos de la biología molecular, algunas de las cuales se encuentran implementadas en nuestro país y describiremos a continuación.

\section{Virus herpes simplex}

Los virus herpes simplex (VHS) tipo 1 y tipo 2 pertenecen a la familia Herpesviridae, y poseen $\mathrm{ADN}$ de doble hebra como material genético. Los

Laboratorio de Biología Molecular Clínica Las Condes.

Instituto Chileno Japonés de Enfermedades Digestivas Hospital Clínico San Borja Arriarán.

Laboratorio de Biología Molecular Hospital del Tórax.

Recibido: 31 enero 2003

Aceptado: 31 enero 2003

(Primera parte publicado en el $\mathrm{N}^{\circ} 1$ Vol 19, año 2002). 
Tabla 1. Exámenes de biología molecular de uso clínico en Microbiología

\begin{tabular}{|c|c|c|}
\hline Microorganismo & Metodología & Laboratorio \\
\hline \multicolumn{3}{|l|}{ Virus } \\
\hline Citomegalovirus & $\begin{array}{l}\text { RPC } \\
\text { branched DNA } \\
\text { secuenciación }\end{array}$ & CA, CLC, PUC \\
\hline Enterovirus & RT-PCR & CLC, CA, PUC \\
\hline Virus de Epstein-Barr & $\mathrm{RPC}$ & CLC, HT \\
\hline Virus de hepatitis $\mathrm{C}$ & branched DNA & $\mathrm{HCUCH}$ \\
\hline Virus herpes simplex 1 y 2 & $\mathrm{RPC}$ & CA, CLC, PUC \\
\hline $\begin{array}{l}\text { Virus de inmunodeficiencia } \\
\text { humana }\end{array}$ & branched DNA & $\begin{array}{l}\text { ISP, HCUCH, } \\
\text { CDM }\end{array}$ \\
\hline & secuenciación & ISP \\
\hline Virus papiloma humano & $\mathrm{RPC}$ & PUC \\
\hline \multicolumn{3}{|l|}{ Bacterias } \\
\hline Bartonella henselae & $\mathrm{RPC}$ & CLC, PUC \\
\hline Bordetella pertussis & $\mathrm{RPC}$ & CLC \\
\hline Chlamydia pneumoniae & & $\mathrm{HT}$ \\
\hline Legionella pneumophila & $\mathrm{RPC}$ & CLC, HT \\
\hline Mycoplasma pneumoniae & & $\mathrm{HT}$ \\
\hline Mycobacterium tuberculosis & RPC & CA, CLC, PUC, HT \\
\hline \multirow[t]{2}{*}{ Staphylococcus aureus MR } & PFGE & PUC, ISP \\
\hline & $\mathrm{RPC}$ & CLC \\
\hline \multicolumn{3}{|l|}{ Hongos } \\
\hline Aspergillus spp/Candida spp & $\mathrm{RPC}$ & CLC \\
\hline Pneumocystis carinii & $\mathrm{RPC}$ & CLC, HT \\
\hline
\end{tabular}

CA: Clínica Alemana, CLC: Clínica Las Condes, HCUCH: Hospital Clínico Universidad de Chile, PUC: Pontificia Universidad Católica, ISP: Instituto de Salud Publica, CDM: Centro Diagnóstico Molecular Bios Chile., HT: Hospital del Tórax.

métodos de identificación clínica de VHS 1 y 2 incluyen métodos directos como la tinción de Tzanck, detección por ELISA de antígenos virales, cultivos virales y métodos indirectos como la determinación de inmunoglobulinas. Todos estos métodos son de poca sensibilidad y especificidad y es en este contexto que los métodos moleculares constituyen una alternativa diagnóstica ${ }^{1}$. Los métodos moleculares se basan en la amplificación por la reacción de polimerasa en cadena- RPC (o PCR-Polymerase Chain Reaction en inglés $)^{2}$ del gen de la enzima ADN polimerasa $^{3}$ o del gen timidina kinasa ${ }^{4}$. La amplificación de la enzima ADN polimerasa permite la detección simultánea de varios virus de la familia Herpesviridae (VHS 1 y 2, varicela-zoster, citomegalovirus, virus de Epstein-Barr y HHV6) y esto se debe al $80 \%$ de homología del gen de la ADN polimerasa de VHS 1 y 2 con la ADN polimerasa de otros miembros de la familia Herpesviridae. En esta estrategia las regiones de alta homología son las utilizadas para la amplificación por RPC con partidores de consenso y las regiones de baja homología permiten la identificación de cada virus de la familia Herpesviridae a través de sondas específicas. Esta metodología se ha implementado como kit comercial (Pharmagen $\left.{ }^{\circledR}\right)$ y ha sido utilizada en el Centro de Diagnóstico Molecular de BIOS Chile IGSA. Con ella se han realizado alrededor de 566 análisis con 102 $(18,1 \%)$ muestras positivas. En esta casuística se ha detectado la presencia de VHS 1 y 2 en 59 muestras de LCR con 7 casos de coinfección por VHS 1 y VZV. La presencia de más de un agente viral de la familia herpes es un hallazgo de los métodos moleculares y ya ha sido descrita previamente ${ }^{5}$. La doble infección se demuestra por la positividad observada simultáneamente en análisis de serología y biología molecular para VHS 1 y VZV. La amplificación por RPC del gen timidina kinasa es otra estrategia de diagnóstico molecular de HSV tipo 1 y 2. Esta estrategia se basa en la similitud de hasta $60 \%$ del gen timidina kinasa entre VHS 1 y 2 . Los partidores utilizados en este ensayo reconocen secuencias homologas entre ambos virus pero que flanquean una región con divergencias internas. Estas divergencias son reconocidas por enzimas de restricción que cortan en forma específica VHS 1 y 2 (Figura 1). Este método utiliza además una tercera enzima HaeIII, que reconoce ambos virus herpes y sirve como control de amplificación. La especificidad de esta metodología ha sido evaluada en muestras de cultivos virales y la sensibilidad se ha calculado en 50 copias virales. En la Tabla 2 se muestra nuestra experiencia clínica de la amplificación del gen timidina kinasa por RPC para el diagnóstico de VHS tipo 1 y 2 . Se observa que en lesiones dermatológicas esta metodología es altamente sensible y especifica; sin embargo, en muestras de LCR se observan falsos negativos. La incapacidad de demostrar la presencia de VHS tipo 1 se debería a la precocidad de la toma de la muestra ( $<48$ horas) ya que la literatura reporta que la eficiencia de los métodos moleculares está en 


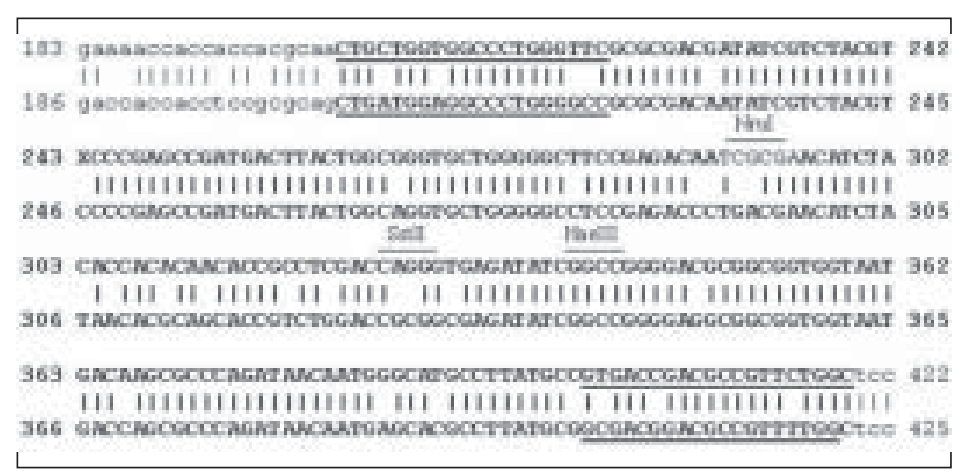

Figura 1. Esquema de la amplificación para herpes simplex tipo 1 y 2 por el gen timidina kinasa. El fragmento amplificado común para ambos virus es digerido con las enzimas de restricción NruI y SstII para diferenciar VHS-1 y VHS-2. HaeIII es una enzima que digiere los amplificados de ambos virus y sirve como método confirmatorio.

Tabla 2. Experiencia clínica con RPC para HSV 1 y 2

\begin{tabular}{lrll}
\hline Tipo de muestra & N & Resultado & Comentario \\
\hline Biopsia de pulmón & 1 & positivo & \\
Lavado broncoalveolar & 1 & $\begin{array}{l}\text { negativo } \\
\text { positivo }\end{array}$ \\
Lesión vesicular facial & 1 & negativo & $\begin{array}{l}\text { 1 caso falso negativo } \\
\text { Lerología positiva) }\end{array}$ \\
Sangre periférica & 3 & negativo & \\
Secreción faríngea & 1 & negativo & \\
Secreción vaginal & 1 & negativo & \\
Tejido cerebral & 1 & negativo & \\
Frotis de lengua & 1 & negativo & \\
Total & 40 & & \\
\hline
\end{tabular}

relación al momento de evolución de la encefalitis $^{6}$. En una serie de 10 pacientes adultos con encefalitis viral aguda por VHS tipo 1, la amplificación por RPC demostró virus herpes inicialmente sólo en pacientes con evolución mayor a 48 horas (8 casos). En los 2 casos que no logró demostrar la presencia del virus, ambos tenían evolución menor a 48 hrs. Al obtener nuevas muestras de LCR, 4 días más tarde en uno y 7 días en el otro caso, ambos resultaron positivos ${ }^{6}$. Estos datos son concordantes con nuestros resultados de falso negativo en un caso con menos de 48 horas de evolución y sugerirían que los métodos moleculares, aunque son un aporte al diagnóstico de la encefalitis viral, no son capaces de la detección de VHS 1 en las etapas iniciales de la encefalitis viral.

\section{Citomegalovirus}

El CMV también pertenece a la familia Herpesviridae y posee especial tropismo hacia fibroblastos, células epiteliales y leucocitos. En estas células, CMV efectúa su reproducción lítica o puede permanecer en estado episomal, habiendo grandes períodos de latencia con reactivaciones ocasionales bajo determinadas circunstancias, como la inmunosupresión inducida en pacientes transplantados ${ }^{7}$. Diversos métodos se han descrito para el diagnóstico de esta reactivación, como la serología, el cultivo de fibroblastos y la antigenemia ${ }^{8-10}$. Sin embargo, en los últimos años han aparecido numerosos reportes sobre la superioridad de los métodos moleculares en el monitoreo de la reactivación de CMV en pacientes inmunosuprimidos, en particular en ubicaciones tisulares ${ }^{11,12}$. Uno de los métodos utilizados es la amplificación por RPC de la región promotora del gen pp65. Este gen codifica para una fosfoproteína de $65 \mathrm{Kda}$ con ubicación en la matriz nuclear y que corresponde a una proteína de expresión tardía. Los partidores utilizados en este ensayo han sido diseñados utilizando la cepa Towne como referencia ${ }^{13}$ y análisis experimentales han demostrado una alta sensibilidad ya que no amplifican otros genomas virales pertenecientes a familia Herpesviridae o de otros microorganismos. Estudios de sensibilidad indican que el método es capaz de detectar desde 4 células infectadas en 100.000 células analizadas y la validación clínica de esta estrategia se realizó correlacionando resultados moleculares con los de otros métodos de uso clínico, observando en 14 casos analizados 1 falso positivo y 1 falso negativo (sensibilidad 93\%, especificidad 93\%) ${ }^{14}$. En nuestro laboratorio hemos analizado 211 determinaciones de CMV, con 28 casos positivos, 179 negativos y 4 inhibiciones. Entre los casos positivos destaca la detección de CMV 7 y 3 días antes del inicio de la sintomatología en un paciente portador de un transplante alogeneico de médula ósea por leucemia mieloide crónica y regresión de la positividad molecular al iniciar el tratamiento (Figura 2) ${ }^{14}$. Estos resultados indican que la amplificación por RPC sería capaz de detectar reactivación viral con una semana de anticipación a la aparición de los síntomas. Existen re- 


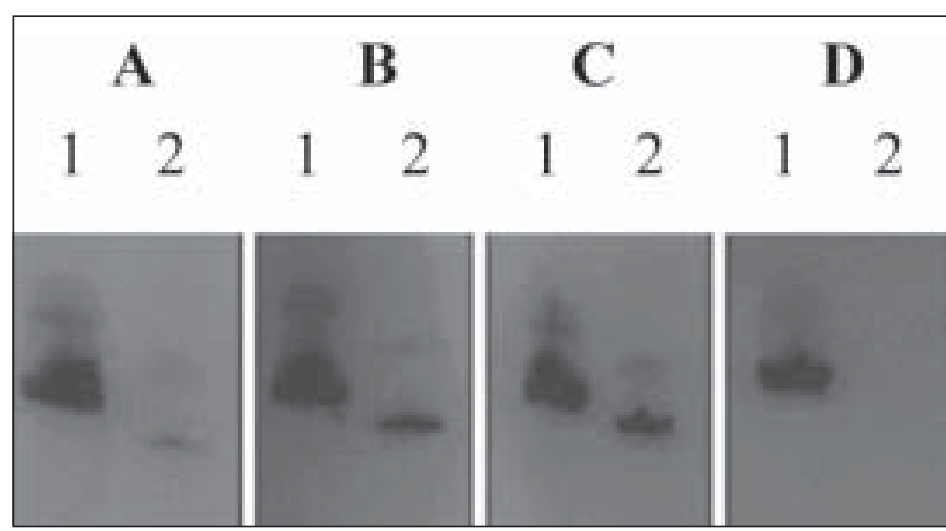

Figura 2. Amplificación positiva para CMV (caso clínico) A: RPC 7 días antes de los síntomas. B: 3 días antes de los síntomas. C: día de inicio de los síntomas e inicio terapia antiviral. D. 3 días de iniciado el tratamiento antiviral. 1: betaglobina humana (control positivo interno, $110 \mathrm{pb}$ ). 2: CMVpp65 (102 pb). Se observa el aumento de intensidad de la banda de CMV entre A y C, y la desaparición de la banda de CMV en D. ${ }^{14}$. medio y superior del estómago y una similar proporción en los dos tipos histológicos predominantes de CG (intestinal y difuso) $)^{21,26-30}$. Dado que en Chile el CG es la primera causa de muerte por cán$\mathrm{cer}^{31}$, hemos analizado las características clínico-patológicas del CG asociado a VEB en una serie de 185 casos consecutivos ${ }^{32}$. Nuestros resultados indican una alta frecuencia de asociación entre VEB y CG ya que observamos 31 casos $(16,8 \%)$ positivos, lo que representa la segunda frecuencia más alta del mundo, una distribución similar entre ambos sexos, una fuerte asociación con la ubicación en el tercio superior

portes en la literatura que indican que esta anticipación podría ser de por lo menos 10 días y que esta precocidad sería mayor en muestras de células mononucleares de sangre periférica que en muestra de suero ${ }^{15,16}$.

\section{Virus de Epstein-Barr}

El VEB también pertenece a la familia Herpesviridae y aunque originalmente fue descrito asociado al linfoma de Burkitt, posteriormente se ha vinculado a patologías benignas como la mononucleosis infecciosa y otras neoplasias linfoides como enfermedad de Hodgkin y linfomas B en pacientes inmunosuprimidos ${ }^{17}$. El virus de EpsteinBarr también ha sido descrito en neoplasias epiteliales como carcinoma nasofaríngeo ${ }^{18}$ y linfoepitelioma gástrico ${ }^{19}$ y recientemente también ha sido descrito en cáncer gástrico (CG) en una proporción de 8 a $20 \%{ }^{20}$. Las evidencias que apoyan la existencia de una asociación entre VEB y CG son la expresión de VEB exclusivamente en células tumorales ${ }^{21}$ (Figura 3), la demostración de genoma monoclonal de VEB en las células tumorales (lo que indica que la infección viral precede a la expansión neoplásica) ${ }^{22}$, la presencia de títulos de anticuerpos anti-VEB significativamente elevados en pacientes con CG asociado a VEB respecto a pacientes controles ${ }^{22-24}$, y la existencia de un patrón histológico único denominado "lace pattern" 25. El CG asociado a VEB se caracteriza además por un predominio en hombres, una ubicación principalmente en el tercio

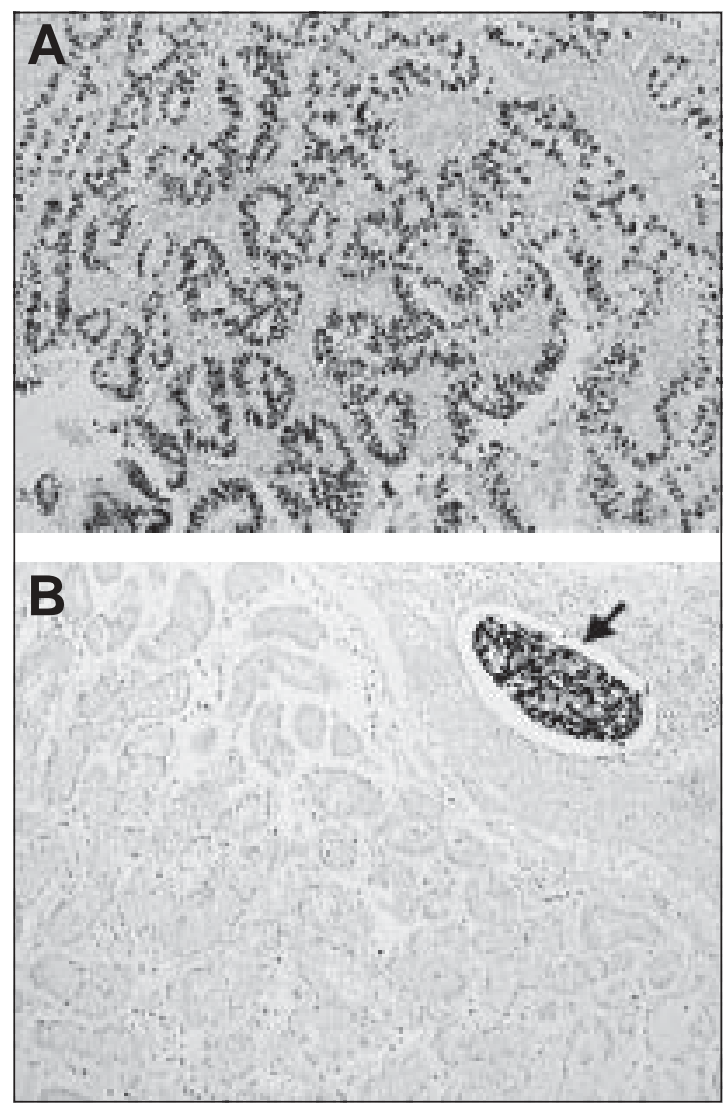

Figura 3. Hibridación in situ para virus de Epstein-Barr. A. Hibridación positiva en un caso de CG de tipo histológico "intestinal" en el cual se observan las estructuras glandulares y tinción positiva en todos los núcleos tumorales. B. Hibridación positiva en un émbolo tumoral (flecha), pero no en mucosa gástrica normal. 


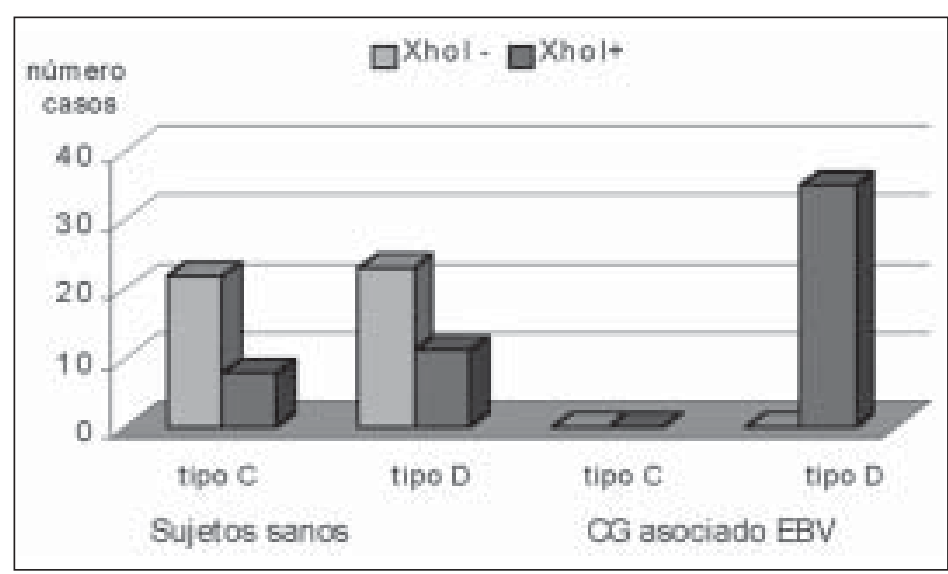

Figura 4. Genotipos del virus de Epstein-Barr en sujetos sanos y pacientes con cáncer gástrico. Se observa la presencia de 4 cepas en la población sana pero una sola cepa (tipo D XhoI positiva) en CG asociado a VEB.

Sin embargo, estos hallazgos deben ser confirmados mediante otras metodologías como "hibridación in situ", dada la fuerte controversia respecto del probable rol carcinogenético de VPH en cáncer pulmonar.

\section{Bordetella pertussis}

La coqueluche o tos ferina es una infección aguda del aparato respiratorio causada principalmente por $B$. pertussis con una alta tasa de mortalidad en lactantes menores de tres meses de vida ${ }^{39}$. Dado que la mayoría de los casos mortales son lactantes que no han alcanzado la inmunización completa $^{40,41}$ se ha propuesto que todo

del estómago y predominio del patrón histológico difuso $^{32}$. Dado que estas características difieren de lo descrito previamente en países asiáticos y europeos $^{21,26-28,30,33}$, pero es similar al descrito en México $^{34}$ y en descendientes mexicanos en E.U.A..$^{35}$, hemos sugerido la presencia de un perfil único de CG asociado a VEB en Latinoamérica $^{32}$. También hemos caracterizado el genotipo de VEB en casos de CG. Nuestros resultados se muestran en la Figura 4 donde se observa la presencia de 4 cepas en la población sana, pero sin embargo, una sola de ellas se encuentra en forma exclusiva en los sujetos con CG. Este resultado contradice la hipótesis aceptada que las cepas de VEB tienen asociaciones geográficas y no están relacionadas con neoplasias específi$\mathrm{cas}^{36}$. Nuestros resultados indican que sujetos sanos portadores de la cepa tipo $\mathrm{D}$, Xhol positivo serían el único grupo en riesgo de desarrollar CG asociado a VEB entre la población sana (manuscrito enviado a publicación).

\section{Virus papiloma humano}

El virus papiloma humano (VPH) que pertenece a la familia Papovaviridae, tiene especial tropismo hacia tejidos epiteliales. En determinadas circunstancias el VPH puede no producir viriones maduros y permanece de manera episomal en estado de latencia o bien, puede integrarse de manera estable al material genético celular ${ }^{37}$. Nuestra experiencia con VPH es fundamentalmente su detección en el cáncer de esófago y pulmón. Recientemente hemos detectado a través de RPC genotipo-específico un 46\% de VPH-16 en carcinomas escamosos queratinizantes de pulmón ${ }^{38}$. menor de tres meses, con diagnóstico de coqueluche debiera ser hospitalizado para monitoreo de su función respiratoria ${ }^{42}$. Los métodos de diagnóstico habitual son el cultivo microbiológico ${ }^{43} \mathrm{y}$ la inmunofluorescencia directa a partir de exudado nasofaríngeo ${ }^{44}$. Sin embargo, ambos se caracterizan por una baja especificidad y sensibilidad y en este contexto, la detección molecular de $B$. pertussis en muestras directas de aspirado nasofaríngeo podría ser considerado como un método alternativo ${ }^{45,46}$. Por otra parte, los resultados de la amplificación por RPC pueden ser cuantificados, lo cual podría tener implicancias en predecir de la severidad de la enfermedad y de este modo utilizarse como parámetro de hospitalización. Para validar estas hipótesis analizamos aspirado nasofaríngeo o sangre periférica de 132 pacientes ambulatorios y 64 hospitalizados amplificando el elemento repetido invertido RSBP-1 de B. pertussis ${ }^{47}$. En 13 pacientes en los que se realizó RPC e IFD, 7 (53,8\%) fueron positivos por RPC, pero sólo 1 fue confirmado por IFD. Sin embargo, la información clínica en todos los casos positivos fue concordante con el diagnóstico de coqueluche. Al cuantificar la intensidad de la amplificación de RSBP-1, observamos que en los pacientes ambulatorios, el promedio de la intensidad de la amplificación fue 71,2\% (rango $1-150 \%$ ) con respecto de la intensidad del control interno (beta-globina humana). Sin embargo, en pacientes hospitalizados ésta fue de $171 \%$ (10-500\%). La mayor intensidad de amplificación en los pacientes hospitalizados es sugerente de una mayor carga bacteriana en los primeros y apoyaría la hipótesis de que la cuantificación de RSBP-1 podría ser un método de diagnóstico 
rápido y predictivo de severidad de enfermedad en particular en niños menores de 6 meses $^{47}$.

\section{Helicobacter pylori}

Helicobacter pylori es una bacteria Gram negativa, microaerofílica que coloniza la mucosa gástrica. La presencia de $H$. pylori en la mucosa gástrica siempre esta asociada a inflamación o gastritis, pudiendo o no tener manifestaciones clínicas $^{48,49}$. Algunos de los mecanismos patogenéticos de $H$. pylori son la presencia de flagelos, adhesinas, actividad de ureasa $y$, en un porcentaje de bacterias (alrededor de $70 \%$ de los aislados clínicos), la producción de una citotoxina con actividad vacuolizante (VacA) y una proteína asociada a la expresión de citotoxina denomina cagA (citotoxin associated gen A) ${ }^{50}$. H. pylori tiene entre 4 y 6 flagelos, cada uno compuesto por una flagelina mayor (FlaA) y una flagelina menor (FlaB). Ambas moléculas pesan $53 \mathrm{kD}$ pero sólo tienen $58 \%$ de homología entre ellas ${ }^{51}$; sin embargo, ambas moléculas tiene una alta homología con flagelinas de Campylobacter coli y Salmonella typhimurium. La pérdida de FlaA resulta en pérdida de motilidad con una disminuida capacidad de colonización gástrica. Sin embargo, la pérdida de FlaB no resulta en ninguna alteración. H. pylori produce una potente enzima ureasa. La generación de amonio por hidrólisis de la urea se cree que protege a $H$. pylori de la baja concentración de $\mathrm{pH}$, una característica de la mucosa gástrica ${ }^{52}$. Por otra parte, la generación de amonio contribuye al daño de la mucosa gástrica a través de estímulo de la respuesta inflamatoria. Estudios de microscopia electrónica revelan que aunque la gran mayoría de $H$. pylori están flotando en el medio gástrico, un porcentaje de ellos están adheridos a la mucosa gástrica. Algunas de la adhesinas descritas se unirían al grupo sanguíneo de Lewis y el uso de anticuerpos contra antígenos de Lewis han permitido bloquear la unión de $H$. pylori a la mucosa gástrica ${ }^{53}$. H. pylori produce una toxina denominada vacA por su intensa actividad vacuolizante en células epiteliales en cultivo y produce ulceración y daño tisular al ser administrada oralmente en animales experimentales ${ }^{54}$. Aunque todas las cepas de $H$. pylori tienen el gen vacA, sólo 50\% expresa la citotoxina vacA. La estructura genética de vacA corresponde a un mosaico con variaciones en la región media (denominado $\mathrm{m} 1$ y $\mathrm{m} 2$ ) y en la región aminoterminal (denominada s1a, s1b, s2). Varias publicaciones indican que la forma $\mathrm{m} 1 \mathrm{es}$ más activa que la $\mathrm{m} 2$ y que la forma s1a es más activa que la s1b. La forma s2 no tiene actividad.
En asociación con enfermedad ulcerosa péptica, las cepas s1 están en el $90 \%$ de los casos y en su gran mayoría son $\mathrm{s} \mathrm{a}^{55}$. Por otro lado, la frecuencia de úlcera péptica en portadores de la cepa s2 no es mayor que en pacientes contro$\operatorname{les}^{56}$. La presencia del gen A asociado a citotoxina (cagA) ha sido descrita en 38 a $70 \%$ de los aislamientos clínicos ${ }^{57,58}$. Sin embargo, siempre la presencia del gen A se asocia a la producción de la proteína cagA y a una fuerte respuesta inmune, razón por la cual las pruebas serológicas son una buena estrategia para su detección. La presencia de la cepa cagA ha sido asociada al desarrollo de la úlcera gástrica y duodenal y también al desarrollo de gastritis crónica atrófica, la lesión precursora del cáncer gástrico ${ }^{59}$. Recientemente se ha identificado la función de cagA. Esta proteína una vez secretada por $H$. pylori es transportada al interior de la célula epitelial, donde es fosforilada en residuos de tirosina e induce la expresión del factor nuclear-kb y liberación de IL-8, citoquina quimiotáctica para polimorfonuclear $^{60,61}$. Por otra parte, la fosforilación de cagA es un estímulo para la proliferación de la célula epitelial gástrica y también induce reordenamiento del citoesqueleto de la célula epitelial ${ }^{62}$.

\section{Tipificación de microorganismos}

Con el advenimiento de la biología molecular se han utilizado numerosas técnicas para la subtipificación de microorganismos, desplazando a un segundo plano las técnicas de tipificación mediante rasgos fenotípicos ${ }^{63}$. El proceso de tipificación es importante epidemiológicamente para el reconocimiento de brotes de infección, en la detección de transmisión cruzada de patógenos nosocomiales, en la detección de fuentes de infección y particularmente, en el reconocimiento de cepas virulentas de un microorganismo determinado ${ }^{64}$. La técnica de electroforesis en gel de campo pulsado (PFGE, pulsed-field gel electrophoresis) es considerada actualmente el "gold standard" de los métodos de tipificación molecular [65]. En este método el ADN genómico de la bacteria es digerido con enzima de restricción de corte infrecuente y posteriormente los fragmentos resultantes son separados en un gel de agarosa sometido a un campo eléctrico cuya polaridad es cambiada a intervalos variables. El campo pulsado permite una separación clara de fragmentos de ADN de gran tamaño molecular (10-800 kb), los patrones resultantes de la electroforesis se digitalizan para el análisis de las bandas, el cual se ejecuta con software comercialmente disponible (Applied Math, Bio-Rad, BioSystematics, Media 
Cybernetics o Scanalytics). La técnica de PFGE ha probado ser altamente discriminatoria en la tipificación de muchas especies bacterianas; sin embargo, su uso se ha limitado sólo a ciertos centros de referencia por el alto costo que implica su implementación. Como alternativa a esta metodología se han planteado numerosas técnicas de tipificación basadas en amplificación por $\mathrm{RPC}^{65,66}$. Está técnica permite que determinados loci genéticos sean amplificados y examinados en busca de variaciones características de cada cepa. Inicialmente los loci son amplificados con partidores específicos, sometidos a análisis de RFLP (restriction fragment lenght polymorphism) $\mathrm{y}$ visualizados por electroforesis. Esta metodología se ha utilizado en el análisis de diversos loci, los que como condición deben presentar heterogeneidad dentro de la misma especie. Dentro de los loci utilizados se encuentran el operon rRNA en Staphylococcus aureus (ribotipificación), el gen ure $\mathrm{C}$ en $H$. pylori y el gen kat $\mathrm{G}$ de Mycobacterium tuberculosis ${ }^{65}$. Sin embargo, la principal falencia de estos ensayos radica en la limitada región del genoma que puede ser examinada, hecho que resulta en un menor poder de discriminación en comparación con PFGE. Dentro de las técnicas basadas en la amplificación locus específico, nosotros hemos utilizado la región espaciadora 16S-23S del locus rRNA (RS-PCR, Ribosomal Spacer PCR) para la tipificación de cepas nosocomiales de Staphylococcus aureus resistente a meticilina (SAMR). Esta región espaciadora presenta múltiples polimorfismos en secuencia y longitud los que, luego de ser amplificados con partidores específicos, generan patrones de bandas propios de cada clon de $\mathrm{SAMR}^{67,68}$. Nosotros hemos estudiado 40 cepas de SAMR aislados a partir de 3 hospitales de la ciudad de Santiago, analizándolos por RS-PCR y PFGE. El método RS-PCR mostró 5 perfiles alélicos diferentes los que en su totalidad fueron confirmados por PFGE. Esta última técnica distinguió además un subtipo (cepas estrechamente relacionadas) que no fue posible visualizar con RS-PCR. Además RS-PCR demostró ser altamente reproducible luego de la tipificación reiterada de 10 aislamientos diferentes en experimentos consecutivos, resultando los mismos perfiles alélicos. Por ambos métodos se llegó a determinar la existencia de un clon ampliamente diseminado, presente en la mayoría de los aislamientos de SAMR en las tres instituciones analizadas, lo cual indicaría la presencia de un "clon epidémico" ${ }^{69}$, hecho que se ha descrito en otras regiones del mundo ${ }^{70}$. Otro grupo de métodos basados en amplificación por RPC son los denominados
RAPD (random amplified polymorphic DNA) y Rep-PCR (repetitive-PCR). El primero esta basado en que pequeños partidores (10 pb) cuya secuencia es inespecífica y no es dirigida a un locus genético determinado sino que, a bajas temperaturas de alineamiento, hibridiza en forma arbitraria en ciertos sitios cromosómicos con suficiente afinidad para permitir la iniciación de la polimerización ${ }^{65,66}$. De este modo, la presencia de estos sitios en dos puntos en hebras de ADN complementarias en dirección opuestas una a la otra permite la amplificación del fragmento entre estos dos puntos. El número de localizaciones de estos puntos varía según la cepa. Este ensayo es atractivo porque sirve para la tipificación de cualquier microorganismo (por ej. bacterias o levaduras) y presenta un alto poder de discriminación. Sin embargo, este método posee baja reproducibilidad y es de difícil interpretación. Rep-PCR se basa en la presencia de secuencias repetitivas presentes en casi todas las especies de bacterias que pueden ser utilizadas como secuencias de consenso para la hibridización de partidores que inician la amplificación en estos sitios ${ }^{71}$. Estas secuencias se ubican típicamente en varios sitios del genoma bacteriano, así cuando dos secuencias repetidas son localizadas una cerca de la otra, la región flanqueada puede ser efectivamente amplificada. Para este efecto se han utilizado principalmente secuencias repetitivas extragénicas palindrómicas, identificadas en muchos miembros de la familia Enterobacteriaceae. La misma estrategia se ha usado con otras secuencias repetitivas, como secuencias de los operones ribosomales, secuencias de inserción y secuencias Shine Dalgarno (sitio de fijación de ribosoma). Este método ha mostrado buena reproducibilidad, bajo costo, baja complejidad y un poder de discriminación que depende de la secuencia repetitiva analizada ${ }^{71}$. El último paso en el desarrollo de estrategias para tipificación ha sido el surgimiento de técnicas basadas en secuenciación de ADN lo que se ha visto favorecido por la aparición de técnicas de secuenciación automática ${ }^{65,66}$. La secuenciación completa de algunos microorganismos y su posterior análisis han sentado las bases para el desarrollo de nuevos ensayos que permiten discriminar entre diferentes clones. Junto con ello, la creación de una red abierta para la comparación objetiva de secuencias de determinados genes bacterianos denominado multilocus sequence typing (MLST) constituye otro avance en la tipificación de microorganismos $^{72}$. En MLST, 6 a 8 genes constitutivos de una bacteria determinada son secuenciados, y con las secuencias se genera un perfil alélico que 
será comparado vía internet con otros perfiles alélicos de cepas aisladas en diferentes partes del mundo. Esta iniciativa es valiosa ya que es un primer paso para la constitución de una base de datos de una red epidemiológica global ${ }^{72}$.

\section{Mycobacterium tuberculosis}

La tuberculosis es causada por microorganismos del género Mycobacterium tuberculosis complex (MTC) que incluye las especies $M$. tuberculosis, M. bovis, M. africanum y M. microti. El bacilo tuberculoso es delgado, de 1 a $4 \mu \mathrm{m}$ de longitud y posee una pared más compleja que todas las bacterias conocidas ${ }^{73}$. El diagnóstico de tuberculosis es a menudo difícil y aún esta basado en las técnicas de microscopia y cultivo en medio Lowenstein-Jensen ${ }^{73}$ que requieren a lo menos 30 días de incubación. Como una alternativa de diagnóstico rápido han surgido los métodos de amplificación de ácidos nucleicos de los cuales existen diversos kits comerciales ${ }^{74,75}$. Sin embargo, por el alto costo de estos reactivos y por la necesidad de establecer formatos que permitan amplificar distintas secuencias de $M$. $t u$ berculosis bajo un mismo programa de amplificación, diseñamos un sistema basado en la amplificación de un fragmento de IS6110 de M. tuberculosis y hemos utilizado partidores reportados en la literatura para amplificar una región interespaciadora de ADN codificante para genes ribosomales ${ }^{76-79}$. IS6110 se encuentra en alto número de copias (50-60) en el interior del genoma de $M$. tuberculosis s $^{80}$ y es altamente específica. Los partidores diseñados para $M$. tuberculosis generan un fragmento de $120 \mathrm{pb}$ y la especificidad del amplicón es confirmada con la enzima de restricción Alu I. El análisis de sensibilidad, que se realizó diluyendo una muestra con recuento conocido usando como matriz líquido pleural, indicó que podemos detectar un mínimo de 2 bacilos en una muestra clínica (equivalente a 120 moléculas de IS6110). Sin embargo, la sensibilidad del método, en correlación con el cultivo de Lowenstein-Jensen es limitada (45\%) aunque la especificidad es muy alta $(100 \%)^{78,81}$. Estos datos concuerdan con los obtenidos usando partidores reportados para genes ribosomales ${ }^{79}$. La baja sensibilidad se puede deber a los procedimientos asociados a la extracción del ácido nucleico de MTB puesto que la estructura de la pared celular es dos veces más fuerte que la de los bacilos Gram negativos ${ }^{73}$. Esta etapa es crítica en la eficiente liberación del material genético para poder posteriormente ser amplificado. Ac- tualmente estamos desarrollando métodos de RPC anidado para lograr una mayor sensibilidad, RPC doble y RPC de transcripción reversa, para detectar ARN mensajero de MTB, lo cual puede correlacionar con infección activa, o como monitoreo de la terapia antituberculosa y aumentar a la vez la sensibilidad en la detección del bacilo tuberculoso ${ }^{82}$.

\section{Pneumocystis carinii}

Pneumocystis carinii spp hominis es un patógeno que provoca cuadros de neumopatía severa en pacientes inmunosuprimidos. Se admite que la mayoría de las personas se infectan por $P$. carinii posiblemente antes de los cuatro años de vida, pudiendo existir transmisión madre-hijo ${ }^{83}$ pero la infección es asintomática y el microorganismo permanece latente (desarrollo de formas quísticas) reactivándose sólo cuando existe una disminución de la inmunidad ${ }^{84}$. El diagnóstico de $P$. carinii se construye por la visualización microscópica o inmunofluorescencia (IF) de muestras de esputo, lavado broncoalveolar o biopsia transbronquial. Sin embargo, estos métodos presentan sensibilidad y especificidad limitadas, en particular en muestras no obtenidas en forma no invasora como secreción bronquial (SB) ${ }^{85}$. Se ha reportado que diversos formatos de amplificación por RPC presentan un rendimiento diagnóstico promisorio $^{86-88}$ aunque su detección en pacientes inmunocomprometidos sin enfermedad por $P$. carinii sugiere la presencia de colonización o infección subclínica, lo cual podría disminuir el valor diagnóstico de esta metodología. En nuestro laboratorio diseñamos y validamos un método "in house" para la detección de P. carinii en lavado broncoalveolar (LBA) y SB de pacientes con sospecha clínica de neumonía intersticial por P. carinii $^{89}$. Nuestro método amplifica, con una sensibilidad de 100 copias genómicas, un fragmento de $191 \mathrm{pb}$ de la subunidad mayor del ARN $23 \mathrm{~S}$ ribosomal, la cual es digerida por la enzima XhoI como método confirmatorio. Al comparar la amplificación por RPC con la tinción de azul de toluidina (TAT) en LBA observamos porcentajes similares de positividad [59,3\% (32/54) para RPC y $51,9 \%$ (28/54) para TAT]. Sin embargo, en muestras de obtención no invasora (SB) la TAT tuvo un porcentaje de casos positivos de $22,5 \%$ (9/40) con respecto la amplificación por RPC [35\% (14/40)]. Tomados en conjunto y usando el diagnóstico clínico final de neumonía intersticial por $P$. carinii como gold standard, la sensibilidad y especificidad de la RPC fue de 93,8 y 
$100 \%$ respectivamente versus 66,7 y $87,5 \%$ de la TAT. Estos resultados indican que la muestra de SB sería adecuada para el diagnóstico de neumonía intersticial por $P$. carinii utilizando amplificación por $\mathrm{RPC}^{90}$. El uso de método más sensibles como RPC doble o RPC anidado para mejorar la sensibilidad, han presentado una alta proporción de falsos positivos lo que implica una pérdida de correlación clínica ${ }^{91}$.

\section{Microorganismos "atípicos"}

En Chile, en el año 1998 las neumonías fueron la primera causa de muerte en la población, sin distinción de sexo ni edad, con una tasa de 39,9 por 100.000 habitantes. Las neumonías adquiridas en la comunidad (NAC) que tienen un curso clínico y características radiológicas diferentes a las neumonías de origen neumocóccico, se denominan "neumonías atípicas"92. Comúnmente se atribuye a ciertos microorganismos, también llamados "atípicos", la causa de esta patología. Ellos incluyen a Chlamydia pneumoniae, Mycoplasma pneumoniae y Legionella pneumophyla ${ }^{92}$. Sin embargo, en la rutina asistencial sólo es posible llegar a la identificación del agente causal de las neumonías en una minoría de casos, debido a las limitaciones de los métodos de diagnóstico etiológico. El difícil diagnóstico de los agentes atípicos se fundamenta en la falta de un método gold standard o referencia disponible para su uso clínico. Los métodos actuales son el análisis serológico a través de IFI, puesto que el cultivo de estas bacterias es complicado. Por esta razón y por su alta sensibilidad y especificidad, los métodos de diagnóstico molecular como la RPC, han surgido como una alternativa diagnóstica a ser evaluada ${ }^{93,94}$. Además, dado que los métodos moleculares permiten el análisis de muestras respiratorias, es posible usar expectoración o esputo inducido, evitando la ejecución de métodos invasores. Mycoplasma pneumoniae es la causa más frecuente de neumopatías atípicas en niños y adultos y es un agente pleomórfico sin pared celular, perteneciente al género Mycoplasma. $M$. pneumoniae se une al epitelio respiratorio introduciéndose entre los cilios de éste y ocasiona daño directo, aparentemente por la producción de radicales libres. Este daño celular induce ciliostasis, lo que explica la tos persistente que produce la infección por este microorganismo. Chlamydia pneumoniae es una bacteria funcionalmente deficitaria, ya que no puede sintetizar ATP, obteniéndolo de la célula huésped; $C$. pneumoniae representa $\sim 8 \%$ de pacientes con $\mathrm{NAC}^{95}$. Legionella pneumophyla tiene baja incidencia en
NAC pero constituye una infección grave que requiere mayor dosis del agente antibacteriano $0^{96}$. Nuestra experiencia en la detección molecular, a través de RPC de microorganismos atípicos, ha demostrado no ser concordante con la información que ha sido obtenida mediante métodos serológicos ${ }^{95}$. Si bien es cierto, usando este último tipo de métodos, la seroprevalencia de cada microorganismo es de aproximadamente 8 a $10 \%$ para pacientes con NAC, nuestros hallazgos a través de RPC son mucho más bajos (2 a 5\%), cuando se emplean muestras respiratorias como expectoración o LBA. Sin embargo, la dificultad de disponer de métodos gold standard dificulta la evaluación de los ensayos moleculares como la RPC. En todo caso, siendo la especificidad bastante alta, se hace necesario disponer de alternativas moleculares más sensibles para la eficiente detección de estos agentes infecciosos, marcando un desafío a ser resuelto en un futuro cercano.

\section{Infecciones micóticas: Candidiasis y aspergilosis}

La frecuencia de infecciones por hongos, Candida albicans y Aspergillus fumigatus, se ha incrementado en los últimos años debido al aumento de pacientes inmunosuprimidos por el uso de quimioterapia en altas dosis, y por el uso masivo de antimicrobianos de amplio espectro. Los métodos estándares para la detección de infecciones micóticas más frecuentes como el cultivo micótico y la histopatología, tienen una reconocida baja sensibilidad y especificidad, por lo que se han desarrollado métodos moleculares para mejorar el diagnóstico ${ }^{97}$. En nuestro laboratorio desarrollamos partidores específicos para Candida spp y Aspergillus sp basándonos en la amplificación por RPC de la subunidad 5,8 S del ARN ribosomal. La validación de esta estrategia se muestra en la Figura 5 donde se observa amplificación de un fragmento de 124 pb de la subunidad 5,8 $\mathrm{S}$ para varias especies de candida y aspergilus pero no para $P$. carinii, un agente importante en el diagnóstico diferencial de las micosis sistémicas. La experiencia clínica con este método se muestra en la Tabla 3 donde se observan los resultados de 89 casos de mucosa o secreción nasal realizados. Los casos positivos representan 5,7\% del total de los casos analizados, lo cual es significativamente menor a lo reportado en la literatura que llega hasta $42 \%$. En esta serie preliminar sería interesante la correlación con otros métodos como cultivo e histología. 


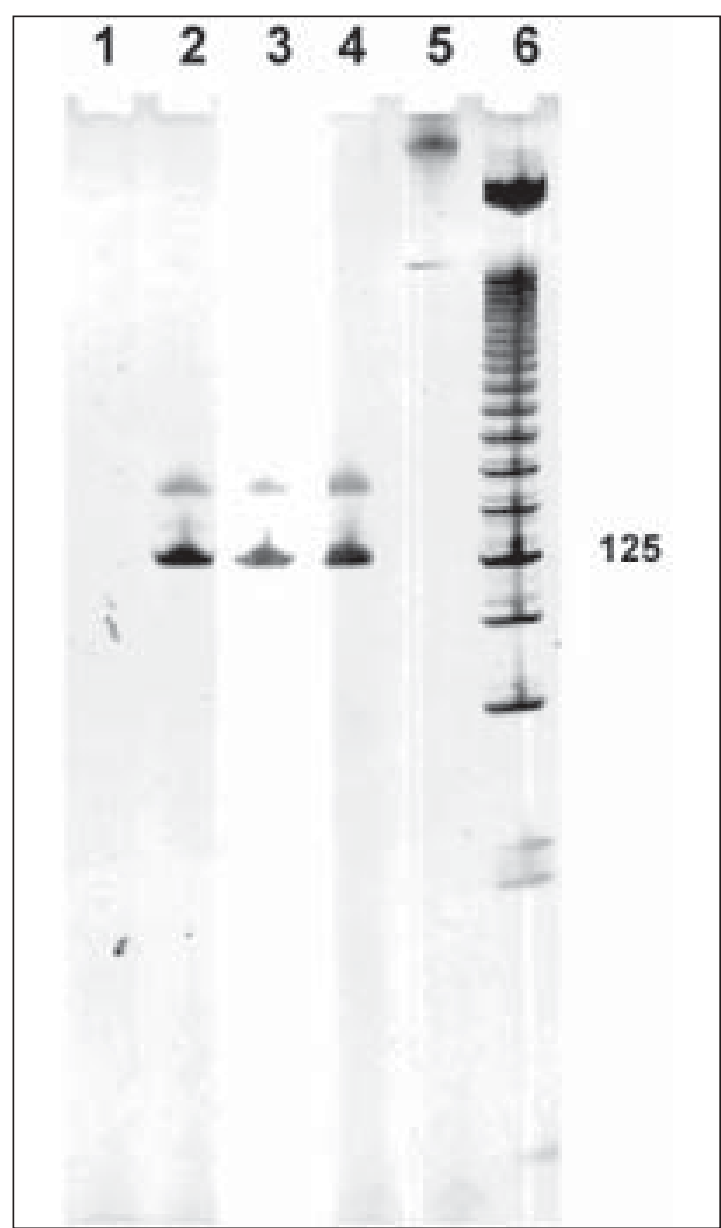

Figura 5. Amplificación por RPC de gen 5,8S, Candida sp. y Aspergillus sp. Carril 1, control negativo, carril 2 Candida albicans (cultivo), carril 3 Candida tropicalis (cultivo), carril 4 Aspergillus fumigatus (cultivo), carril 5 Pneumocystis carinii (caso clínico), carril 6 Marcador peso molecular. Se observa amplificación en carriles 2 a 4 correspondientes a muestra de Candida sp y Aspergillus sp. El carril 5 correspondiente a $P$. carinii no muestra de evidencias de amplificación por RPC.

Tabla 3. Amplificación por RPC de Candida spp y Aspergillus spp en muestras de mucosa nasal

\begin{tabular}{lcccc}
\hline Tipo muestra & resultado & $\mathbf{N}$ & $\%$ & \\
\hline Pólipo nasal & negativo & 23 & 92,0 & \\
& positivo & 1 & 4,0 & \\
& inhibido & 1 & 4,0 & \\
& & 25 & & $5(5,6 \%)$ \\
Secreción & negativo & 59 & 92,2 & \\
sinusitis & positivo & & 4 & 6,3 \\
& inhibido & & 1 & 1,6 \\
Total & & 64 & & \\
\hline
\end{tabular}

\section{Resumen}

Las aplicaciones diagnósticas de la biología molecular para enfermedades infecciosas son extremadamente variadas y aplicables a cualquier problema diagnóstico. En agentes virales de la familia Herpesviridae, los más usados se basan en la amplificación del gen de la enzima ADN polimerasa que permite la detección de virus herpes simplex (VHS) 1 y 2, virus varicela-zoster (VVZ), citomegalovirus (CMV), virus de EpsteinBarr (VEB) y herpesvirus humano (HVH) 6 en forma simultánea. Esta metodología ha detectado la coinfección por VHS 1 y VZV en muestras de líquido cefalorraquídeo. En CMV son utilizados en el monitoreo de la reactivación de CMV en pacientes inmunosuprimidos siendo capaz de detectar reactivación viral con una semana de anticipación a la aparición de los síntomas. Los métodos moleculares han permitido la identificación del VEB en una proporción de 8 a $20 \%$ de casos de cáncer gástrico los cuales poseen una cepa única a pesar de la presencia de múltiples cepas en la población sana. Estas asociaciones entre virus y cáncer también se han descrito para el virus papiloma humano y cáncer pulmonar. En agentes bacterianos, la detección y cuantificación de Bordetella pertussis es otra aplicación relevante ya que podría convertirse en un método de diagnóstico rápido y predictivo de severidad de enfermedad en niños menores de 6 meses. La caracterización de cepas de Helicobacter pylori en relación con cáncer gástrico y enfermedad ulcerosa péptica, y la caracterización de cepas nosocomiales de Staphylococcus aureus resistente a meticilina (SAMR), son ejemplos de las potencialidades de los métodos moleculares en la tipificación de microorganismos. En el diagnóstico de agentes causantes de patologías respiratorias como Mycobacterium tuberculosis, Pneumocystis carinii y agentes "atípicos" de infecciones respiratorias, estos métodos han permito el diagnóstico a partir de muestras de obtención no invasora. Finalmente, también han demostrado su aporte en el diagnóstico de infecciones micóticas (candidiasis y aspergilosis), $\mathrm{n}$ particular en pacientes inmunocomprometidos.

\section{Agradecimientos}

Se agradece la colaboración de Edwig Rodríguez Q.F. en la elaboración de la sección Mycobacterium tuberculosis. Este trabajo ha sido financiado parcialmente por 
el proyecto Métodos de Vigilancia Epidemiológica, Subdirección Académica Clínica Las Condes.

\section{Bibliografía}

1.- Johnson G, Nelson S, Petric M, Tellier R. Comprehensive PCR-based assay for detection and species identification of human herpesviruses. J Clin Microbiol 2000; 38: 3274-9.

2.- Corvalán A. Biología Molecular en Infectología. Parte I Desarrollo y aplicaciones. Rev Chil Infect 2002; 19: 14-24.

3.- Tenorio A, Echevarría J E, Casas I, Echevarría J M, Tabares E. Detection and typing of human herpesviruses by multiplex polymerase chain reaction. J Virol Methods 1993; 44: 261-9.

4.- Aurelius E, Johansson B, Skoldenberg B, Staland A, Forsgren M. Rapid diagnosis of herpes simplex encephalitis by nested polymerase chain reaction assay of cerebrospinal fluid. Lancet 1991; 337: 189-92.

5.- Tang Y W, Espy M J, Persing D H, Smith T F. Molecular evidence and clinical significance of herpesvirus coinfection in the central nervous system. J Clin Microbiol 1997; 35: 2869-72.

6.- Studahl M, Bergstrom T, Hagberg L. Acute viral encephalitis in adults-a prospective study. Scand J Infect Dis 1998; 30: 215-20.

7.- Britt W J. A.C.A.C., in: Fields Virology, Third edition, Philadelphia, Lippincott-Raven Publishers, 1996; 2493-513.

8.- Tanabe $\mathrm{K}$, Tokumoto $\mathrm{T}$, Ishikawa $\mathrm{N}$ et al. Comparative study of cytomegalovirus (CMV) antigenemia assay, polymerase chain reaction, serology, and shell vial assay in the early diagnosis and monitoring of CMV infection after renal transplantation. Transplantation 1997; 64: 1721-5.

9.- Bein G, Bitsch A, Hoyer $J$ et al. A longitudinal prospective study of cytomegalovirus pp65 antigenemia in renal transplant recipients. Transpl Int 1993; 6: $185-90$.

10.- Landry M L, Ferguson D. Comparison of quantitative cytomegalovirus antigenemia assay with culture methods and correlation with clinical disease. J Clin Microbiol 1993; 31: 2851-6.

11.- Stephan F, Fajac A, Grenet D et al. Predictive value of cytomegalovirus DNA detection by polymerase chain reaction in blood and bronchoalveolar lavage in lung transplant patients. Transplantation 1997; 63: 1430-5.

12.- Kusne S, Manez R, Frye B L et al. Use of DNA amplification for diagnosis of cytomegalovirus enteritis after intestinal transplantation. Gastroenterology 1997; 112: 1121-8.

13.- Depto A S, Stenberg R M. Regulated expression of the human cytomegalovirus pp65 gene: octamer sequence in the promoter is required for activation by viral gene products. J Virol 1989; 63: 1232-8.

14.- Aguayo F, Corvalán A. Diagnóstico molecular de citomegalovirus. Rev Med Clínica Las Condes, 1999; 10: 28-31.

15.- Boeckh M, Gallez-Hawkins G M, Myerson D, Zaia J A, Bowden R A. Plasma polymerase chain reaction for cytomegalovirus DNA after allogeneic marrow transplantation: comparison with polymerase chain reaction using peripheral blood leukocytes, pp 65 antigenemia, and viral culture. Transplantation 1997; 64: $108-13$.
16.- Brytting M, Mousavi-Jazi M, Bostrom L et al. Cytomegalovirus DNA in peripheral blood leukocytes and plasma from bone marrow transplant recipients. Transplantation 1995; 60: 961-5.

17.- Rickinson A B, Kieff E. Epstein-Barr Virus. En: Fields B, K.D., Howley P, et al (eds.) Fields Virology 3rd Ed. Philadelphia: Lippincont-Raven Publishers1996; 2397 445.

18.- Hausen H Z. Epstein-Barr virus in human tumor cells. Int Rev Exp Pathol 1972; 11: 233-58.

19.- Watanabe H, Enjoji M, Imai T. Gastric carcinoma with lymphoid stroma. Its morphologic characteristics and prognostic correlations. Cancer 1976; 38: 23243.

20.- Takada K. Epstein-Barr virus and gastric carcinoma. Mol Pathol 2000; 53: 255-61.

21.- Tokunaga M, Land C E, Uemura Y, Tokudome T, Tanaka S, Sato E. Epstein-Barr virus in gastric carcinoma. Am J Pathol 1993; 143: 1250-4.

22.- Imai S, Koizumi S, Sugiura M et al. Gastric carcinoma: monoclonal epithelial malignant cells expressing Epstein-Barr virus latent infection protein. Proc Natl Acad Sci USA 1994; 91: 9131-5.

23.- Levine P H, Stemmermann G, Lennette E T, Hildesheim A, Shibata D, Nomura A. Elevated antibody titers to Epstein-Barr virus prior to the diagnosis of Epstein-Barr-virus-associated gastric adenocarcinoma. Int J Cancer 1995; 60: 642-4.

24.- Shinkura R, Yamamoto N, Koriyama C, Shinmura Y, Eizuru Y, Tokunaga M. Epstein-Barr virus-specific antibodies in Epstein-Barr virus-positive and -negative gastric carcinoma cases in Japan. J Med Virol 2000; 60: 411-6.

25.- Uemura $Y$, Tokunaga $M$, Arikawa $J$ et al. A unique morphology of Epstein-Barr virus-related early gastric carcinoma. Cancer Epidemiol Biomarkers Prev 1994; 3: $607-11$

26.- Selves J, Bibeau F, Brousset P et al. Epstein-Barr virus latent and replicative gene expression in gastric carcinoma. Histopathology 1996; 28: 121-7.

27.- Galetsky S A, Tsvetnov V V, Land C E et al. EpsteinBarr-virus-associated gastric cancer in Russia. Int $\mathrm{J}$ Cancer 1997; 73: 786-9.

28.- Yuen S T, Chung L P, Leung S Y, Luk I S, Chan S Y, Ho J. In situ detection of Epstein-Barr virus in gastric and colorectal adenocarcinomas. Am J Surg Pathol 1994; 18: 1158-63.

29.- Harn H J, Ho L I, Chung W H, Lin J J, Lee H S, Lee W H. Epstein-Barr virus-associated typical gastric carcinoma detected by in situ hybridization and polymerase chain reaction. J Clin Gastroenterol 1995; 20: $253-4$.

30.- Ott G, Kirchner T, Muller-Hermelink H K. Monoclonal Epstein-Barr virus genomes but lack of EBV-related protein expression in different types of gastric carcinoma. Histopathology 1994; 25: 323-9.

31.- Prieto M. Cánceres Digestivos. Unidad de Cáncer, D.U.d.l.p., Ministerio de Salud Chile, 2000.

32.- Corvalán A, Koriyama C, Akiba S et al. Epstein-Barr virus in gastric carcinoma is associated with location in the cardias and with a diffuse histology: a study in one area of Chile. Int J Cancer 2001; 94: 527-30.

33.- Harn H J, Chang J Y, Wang M W et al. Epstein-Barr virus-associated gastric adenocarcinoma in Taiwan. Hum Pathol 1995; 26: 267-71.

34.- Herrera-Goepfert R, Reyes E, Hernández-Ávila M et al. Epstein-Barr virus-associated gastric carcinoma in Mexico: analysis of 135 consecutive gastrectomies in 
two hospitals. Mod Pathol 1999; 12: 873-8.

35.- Gulley M L, Pulitzer D R, Eagan P A, Schneider B G. Epstein-Barr virus infection is an early event in gastric carcinogenesis and is independent of bcl-2 expression and p53 accumulation. Hum Pathol 1996; 27: 20-7.

36.- Khanim F, Yao Q Y, Niedobitek G, Sihota S, Rickinson A B, Young L S. Analysis of Epstein-Barr virus gene polymorphisms in normal donors and in virusassociated tumors from different geographic locations. Blood 1996; 88: 3491-501.

37.- Gaarenstroom K N, Melkert P, Walboomers J M et al. Human papillomavirus DNA and genotypes: prognostic factors for progression of cervical intraepithelial neoplasia. Int J Gynecol Cancer 1994; 4: 73-8.

38.- Aguayo F M M, Corvalán A, Muñoz M L, Koriyama C, Eizuru Y, Akiba S. Identificación de virus papiloma humano (VPH-16) en carcinoma queratinizante de pulmón. Rev Ch Enf Resp 2002; 18: 83-9.

39.- Sánchez I, Repetto G, Saenger A. Whooping cough epidemiology in Chile (1950-1990). The adult as new reservoir of infection?. Rev Méd Chile 1994; 122: 339-45.

40.- Cherry J D. The epidemiology of pertussis and pertussis immunization in the United Kingdom and the United States: a comparative study. Curr Probl Pediatr 1984; 14: 1-78.

41.- Stojanov S, Liese J, Belohradsky B H. Hospitalization and complications in children under 2 years of age with Bordetella pertussis infection. Infection 2000; 28: 106-10.

42.- Ranganathan S, Tasker R, Booy R, Habibi P, Nadel S, Britto J. Pertussis is increasing in unimmunized infants: is a change in policy needed? Arch Dis Child 1999; 80: 297-9.

43.- Perret C V P, Viviani T et al. Etiología del síndrome coqueluchoideo y rendimiento de las técnicas para el diagnóstico de Bordetella pertussis en pacientes hospitalizados. Rev Chil Infect 1999;16:17-26.

44.- Ewanowich C A, Chui L W, Paranchych M G, Peppler M S, Marusyk R G, Albritton W L. Major outbreak of pertussis in northern Alberta, Canada: analysis of discrepant direct fluorescent-antibody and culture results by using polymerase chain reaction methodology. J Clin Microbiol 1993; 31: 1715-25.

45.- Buck G E. Detection of Bordetella pertussis by rapidcycle PCR and colorimetric microwell hybridization. J Clin Microbiol 1996; 34: 1355-8.

46.- van der Zee A, Vernooij S, Peeters M, van Embden J, Mooi FR. Dynamics of the population structure of Bordetella pertussis as measured by IS1002-associated RFLP: comparison of pre- and post-vaccination strains and global distribution. Microbiology 1996; 142: 347985 .

47.- Corvalán A L J, Aguayo F, Lobos T. Diagnóstico y cuantificación de Bordetella pertussis por reacción de polimerasa en cadena. XVIII Congreso Chileno de Infectología, Pucón, 23-26 agosto 2001. P32.

48.- Dooley C P, Cohen H, Fitzgibbons P L et al. Prevalence of Helicobacter pylori infection and histologic gastritis in asymptomatic persons. N Engl J Med 1989; 321: 1562-6.

49.- Figueroa G, Acuña R, Troncoso M, Portell D P, Toledo M S, Valenzuela J. Helicobacter pylori infection in Chile. Clin Infect Dis 1997; 25: 983-9.

50.- Shimoyama T, Crabtree J E. Bacterial factors and immune pathogenesis in Helicobacter pylori infection. Gut 1998; 43 Suppl 1: S2-5.
51.- Telford J L, Ghiara P, Dell'Orco M et al. Gene structure of the Helicobacter pylori cytotoxin and evidence of its key role in gastric disease. J Exp Med 1994; 179: 1653-8.

52.- Telford J L, Covacci A, Ghiara P, Montecucco C, Rappuoli R. Unravelling the pathogenic role of Helicobacter pylori in peptic ulcer: potential new therapies and vaccines. Trends Biotechnol 1994; 12: 420-6.

53.- Suerbaum S, Michetti P. Helicobacter pylori infection. N Engl J Med 2002; 347: 1175-86.

54.- Schmitt W, Haas R. Genetic analysis of the Helicobacter pylori vacuolating cytotoxin: structural similarities with the IgA protease type of exported protein. Mol Microbiol 1994; 12: 307-19.

55.- Rudi J, Rudy A, Maiwald M, Kuck D, Sieg A, Stremmel W. Direct determination of Helicobacter pylori vacA genotypes and $\operatorname{cag} A$ gene in gastric biopsies and relationship to gastrointestinal diseases. Am J Gastroenterol 1999; 94: 1525-31.

56.- Martínez A, González C, Kawaguchi F et al. Helicobacter pylori: cag A analysis and vacA genotyping in Chile. Detection of a s2/m1 strain. Rev Méd Chile 2001; 129: 1147-53.

57.- Gotteland M, Corvalán A, Sarmiento F et al. Gastric permeability is not increased in children colonized by cagA-positive strains of Helicobacter pylori. Dig Liver Dis 2001; 33: 750-4.

58.- Atherton J C. CagA, the cag pathogenicity island and Helicobacter pylori virulence. Gut 1999; 44: 307-8.

59.- Blaser M J, Pérez-Pérez G I, Kleanthous $H$ et al. Infection with Helicobacter pylori strains possessing $\operatorname{cag} A$ is associated with an increased risk of developing adenocarcinoma of the stomach. Cancer Res 1995; 55: 2111-5.

60.- Chávez E, Sarmiento F, López M, Kakarieka E, Vial M T, Gotteland M. Interleukin-8 levels in gastric biopsies of children colonized by Helicobacter pylori. Rev Méd Chile 1998; 126: 139-43.

61.- Segal E D, Cha J, Lo J, Falkow S, Tompkins L S. Altered states: involvement of phosphorylated cagA in the induction of host cellular growth changes by Helicobacter pylori. Proc Natl Acad Sci USA 1999; 96: 14559-64.

62.- Odenbreit S, Puls J, Sedlmaier B, Gerland E, Fischer W, Haas R. Translocation of Helicobacter pylori cagA into gastric epithelial cells by type IV secretion. Science 2000; 287: 1497-500.

63.- Pfaller M A. Molecular approaches to diagnosing and managing infectious diseases: practicality and costs. Emerg Infect Dis 2001; 7: 312-8.

64.- Mc Gowan J, B M. Infection Control Epidemiology and Clinical Microbiology, in Manual of Clinical Microbiology, Murphy P., Editor. 1995: Washington DC. p. $182-9$

65.- Olive D M, Bean P. Principles and applications of methods for DNA-based typing of microbial organisms. J Clin Microbiol 1999; 37: 1661-9.

66.- Arbeit R. Laboratory Procedures for the Epidemiologic Analysis of Microorganism, in Manual of Clinical Microbiology, M. P, Editor. 1995: Washington DC. p. 190-208.

67.- Kumari D N, Keer V, Hawkey P M et al. Comparison and application of ribosome spacer DNA amplicon polymorphisms and pulsed-field gel electrophoresis for differentiation of methicillin-resistant Staphylococcus aureus strains. J Clin Microbiol 1997; 35: 881-5.

68.- Gurtler V, Barrie H D. Typing of Staphylococcus 
aureus strains by PCR-amplification of variable-length 16S-23S rDNA spacer regions: characterization of spacer sequences. Microbiology 1995; 141: 1255-65.

69.- Lévican J C A, Aguayo F, Lobos T. Tipificación molecular de cepas de Staphylococcus aureus multiresistentes mediante amplificación de la región espaciadora intergénica 16S-23S.XVIII Congreso Chileno de Infectología, Pucón, 23-26 agosto 2001. P31.

70.- Oliveira D C, Tomasz A, de Lencastre H. Secrets of success of a human pathogen: molecular evolution of pandemic clones of meticillin-resistant Staphylococcus aureus. Lancet Infect Dis 2002; 2: 180-9.

71.- van der Zee A, Verbakel H, van Zon J C et al. Molecular genotyping of Staphylococcus aureus strains: comparison of repetitive element sequencebased PCR with various typing methods and isolation of a novel epidemicity marker. J Clin Microbiol 1999; 37: 342-9.

72.- Maiden M C, Bygraves J A, Feil E et al. Multilocus sequence typing: a portable approach to the identification of clones within populations of pathogenic microorganisms. Proc Natl Acad Sci USA 1998; 95: 3140-5.

73.- Farga V. Tuberculosis. 1992, Santiago: Editorial Mediterráneo.

74.- Miller N, Cleary T, Kraus G, Young A K, Spruill G, Hnatyszyn H J. Rapid and specific detection of Mycobacterium tuberculosis from acid-fast bacillus smear-positive respiratory specimens and BacT/ ALERT MP culture bottles by using fluorogenic probes and real-time PCR. J Clin Microbiol 2002; 40: 4143-7.

75.- Chen N H, Liu Y C, Tsao T C et al. Combined bronchoalveolar lavage and polymerase chain reaction in the diagnosis of pulmonary tuberculosis in smearnegative patients. Int $\mathrm{J}$ Tuberc Lung Dis 2002; 6: 350-5.

76.- Borun M, Sajduda A, Pawlowska I, McFadden J J, Dziadek J. Detection of Mycobacterium tuberculosis in clinical samples using insertion sequences IS6110 and IS990. Tuberculosis (Edinb) 2001; 81: 271-8.

77.- Vera-Cabrera L, Hernandez-Vera M A, Welsh O, Johnson W M, Castro-Garza J. Phospholipase region of Mycobacterium tuberculosis is a preferential locus for IS6110 transposition. J Clin Microbiol 2001; 39: 3499-504.

78.- Aguayo F R E, G.A.D.d.M.t.m.a.g.C.c.d.Q.c., Pucón, Chile, Octubre 2001. Detección de M. tuberculosis mediante amplificación genómica. Congreso Chileno de Química Clínica, Pucón, Chile, 2001.

79.- Park H, Jang H, Kim C et al. Detection and identification of mycobacteria by amplification of the internal transcribed spacer regions with genus- and species-specific PCR primers. J Clin Microbiol 2000; 38: 4080-5.

80.- Gordon S V, Heym B, Parkhill J, Barrell B, Cole S T. New insertion sequences and a novel repeated sequence in the genome of Mycobacterium tuberculosis H37Rv. Microbiology 1999; 145: 881-92.

81.- Carrizo A A F, Marcone P, Oyonarte M, Rodríguez E, Navarro J. Técnica de reacción de polimerasa en cadena (PCR) para tuberculosis en lavado bronquioalveolar de pacientes Directo negativo. Cong Chil Enf Resp Valdivia, Chile, 2002.

82.- Hellyer T J, DesJardin L E, Hehman G L, Cave M D, Eisenach K D. Quantitative analysis of mRNA as a marker for viability of Mycobacterium tuberculosis. J Clin Microbiol 1999; 37: 290-5.

83.- Miller R F, Ambrose H E, Novelli V, Wakefield A E.
Probable mother-to-infant transmission of Pneumocystis carinii f. sp. hominis infection. J Clin Microbiol 2002; 40: 1555-7.

84.- Morris A, Beard C B, Huang L. Update on the epidemiology and transmission of Pneumocystis carinii. Microbes Infect 2002; 4: 95-103.

85.- Elvin K M, Bjorkman A, Linder E, Heurlin N, Hjerpe A. Pneumocystis carinii pneumonia: detection of parasites in sputum and bronchoalveolar lavage fluid by monoclonal antibodies. BMJ 1988; 297: 381-4.

86.- Larsen H H, Masur H, Kovacs J A et al. Development and evaluation of a quantitative, touch-down, realtime PCR assay for diagnosing Pneumocystis carinii pneumonia. J Clin Microbiol 2002; 40: 490-4.

87.- Maher N, Vermund S, Lasbury M, Lee C, Bartlett M, Unnasch T R. Development and evaluation of a molecular viability assay for Pneumocystis carinii. J Clin Microbiol 2000; 38: 1947-52.

88.- Olsson M, Stralin K, Holmberg H. Clinical significance of nested polymerase chain reaction and immunofluorescence for detection of Pneumocystis carinii pneumonia. Clin Microbiol Infect 2001; 7: 492-7.

89.- Aguayo F, Gajardo G, Fernández P, Levican J, Lobos T, Corvalán A. Desarrollo y evaluación de un método de amplificación genómica para la detección de $P$. carinii. Enviado a publicación, 2003.

90.- Fernández P V G, Undurraga A, Soler T et al. Diagnóstico de neumonia por $P$. carinii mediante técnica de esputo inducido. Congreso Chileno de Enfermedades Respiratorias, Valdivia, Chile, 2002.

91.- Torres J, Goldman M, Wheat L J et al. Diagnosis of Pneumocystis carinii pneumonia in human immunodeficiency virus-infected patients with polymerase chain reaction: a blinded comparison to standard methods. Clin Infect Dis 2000; 30: 141-5.

92.- Gupta S K, Sarosi G A. The role of atypical pathogens in community-acquired pneumonia. Med Clin North Am 2001; 85: 1349-65, vii.

93.- Qasem J A, Khan Z U, Shiji G, Mustafa A S. Polymerase chain reaction as a sensitive and rapid method for specific detection of Mycoplasma pneumoniae in clinical samples. Microbiol Res 2002; 157: 77-82.

94.- Reischl U, Linde H J, Lehn N, Landt O, Barratt K, Wellinghausen N. Direct detection and differentiation of Legionella spp and Legionella pneumophila in clinical specimens by dual-color real-time PCR and melting curve analysis. J Clin Microbiol 2002; 40: 3814-7.

95.- Lobos T, Saldias F, Cartagena C, Jover E, Álvarez M, Moreno R. [Chlamydia pneumoniae in patients with acquired pneumonia in the Santiago of Chile community]. Rev Méd Chile 1998; 126: 1483-9.

96.- Society T B T. Guidelines for the management of community-acquired pneumonia in adults admitted to hospital. Br J Hosp Med 1993; 49: 346-50.

97.- Turenne C Y, Sanche S E, Hoban D J, Karlowsky J A, Kabani A M. Rapid identification of fungi by using the ITS2 genetic region and an automated fluorescent capillary electrophoresis system. J Clin Microbiol 1999; 37: 1846-51.

98.- Catten M D, Murr A H, Goldstein J A, Mhatre A N, Lalwani A K. Detection of fungi in the nasal mucosa using polymerase chain reaction. Laryngoscope 2001; 111: 399-403.

Correspondencia a:

Alejandro Corvalán R.

E-mail: biomolec@clinicalascondes.cl 